\title{
Entrepreneurial Incentives and the Role of Initial Coin Offerings
}

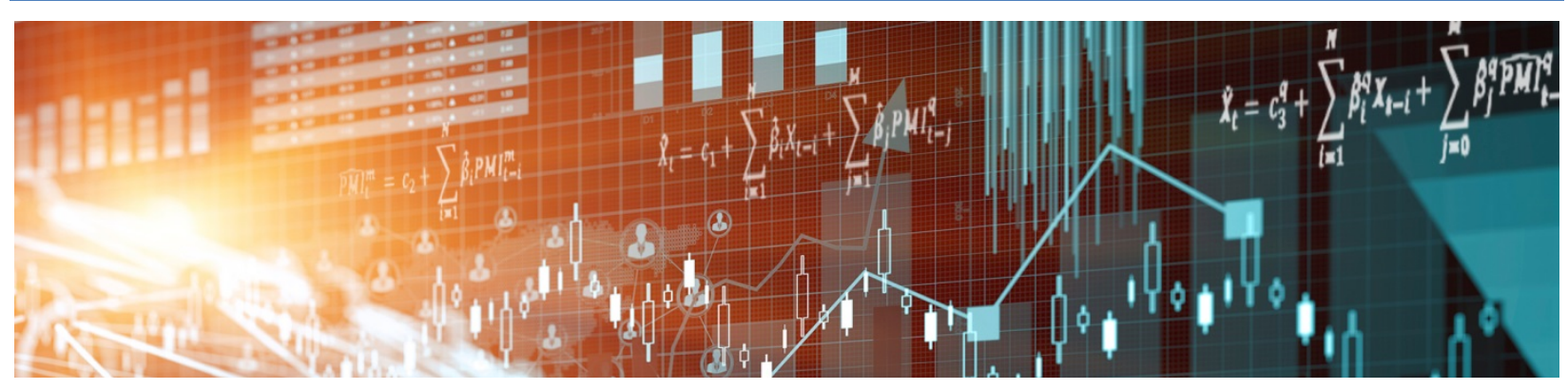

by Rodney Garratt and Maarten R. C. van Oordt 
Bank of Canada Staff Working Paper 2019-18

May 2019

\title{
Entrepreneurial Incentives and the Role of Initial Coin Offerings
}

\author{
by \\ Rodney Garratt ${ }^{1}$ and Maarten R. C. van Oordt ${ }^{2}$ \\ 1 University of California at Santa Barbara \\ Santa Barbara, California, United States \\ garratt@ucsb.edu \\ 2 Currency Department \\ Bank of Canada \\ Ottawa, Ontario, Canada K1A 0 G9 \\ mvanoordt@bankofcanada.ca
}




\section{Acknowledgements}

We thank Toni Ahnert, Jonathan Chiu, Co-Pierre Georg and participants in seminars at the Bank of Canada, the Federal Reserve Bank of Chicago, Purdue University and Indiana University for helpful comments and suggestions. We are grateful to Salman Hussein Hasham and Julia Zhu for research assistance. This paper was written while Garratt was a visiting scholar at the Bank of Canada. The views in this paper do not necessarily reflect those of the Bank of Canada. 


\begin{abstract}
Initial coin offerings (ICOs) are a new mode of financing start-ups that saw an explosion in popularity in 2017 but declined in popularity in the second half of 2018 as regulatory pressure, instances of fraud and reports of poor performance began to undermine their reputation. We examine whether ICOs are a passing fad or a worthwhile form of financing with beneficial economic properties. We do so by examining how financing a start-up through an ICO changes the incentives of an entrepreneur relative to debt and venture capital financing. Depending on market characteristics, an ICO can result in a better or worse alignment of the interests of the entrepreneur and the investors compared with conventional modes of financing. Notably, an ICO can be the only form of financing that induces optimal effort and hence maximizes the net present value of the start-up, and there are projects that should not take place at all unless they can be financed through an ICO.
\end{abstract}

\title{
Bank topics: Asset pricing; Exchange rates
}

JEL code: $G 32$

\section{Résumé}

Les premières émissions de cryptomonnaies (PEC) sont une nouvelle méthode de financement pour les entreprises en démarrage dont la popularité a explosé en 2017. Cet engouement s'est toutefois essoufflé au deuxième semestre de 2018 alors que leur réputation a commencé à souffrir de la pression exercée par les organismes de réglementation, de cas de fraude et de leurs rendements décevants. Dans cette étude, nous tentons de déterminer si les PEC sont une mode passagère ou une méthode de financement viable offrant des avantages économiques. Pour ce faire, nous examinons comment l'utilisation d'une PEC pour financer une entreprise en démarrage influe différemment sur les motivations d'un entrepreneur, comparativement au financement par emprunt et par capital de risque. Selon les caractéristiques du marché, une PEC sera plus ou moins efficace que les méthodes de financement habituelles pour harmoniser les intérêts de l'entrepreneur et des investisseurs. Une PEC peut notamment être la seule forme de financement qui incite à un effort optimal, et donc qui maximise la valeur actualisée nette de l'entreprise en démarrage. En outre, certains projets ne devraient simplement pas être réalisés à moins d'être financés au moyen d'une PEC.

Sujets : Évaluation des actifs; Taux de change

Code JEL : G32 


\section{Non-technical Summary}

Initial coin offerings (ICOs) are a new mode of financing start-ups that saw an explosion in popularity in 2017 but declined in popularity in the second half of 2018 as regulatory pressure, instances of fraud and reports of poor performance began to undermine their reputation. We examine whether ICOs are a passing fad or a worthwhile form of financing with beneficial economic properties.

This paper focuses on ICOs where a start-up raises funds by issuing tokens and selling some or all of these tokens to external investors. The start-up commits to accepting tokens as the only means of payment to buy its products or to purchase goods and services on its platform, and commits to not issuing any additional tokens beyond the pre-committed amount.

We employ a theoretical framework that was previously used to examine whether companies could be financed with debt or venture capital. This framework allows us to assess how financing a start-up through an ICO affects the incentives of an entrepreneur to lead the start-up to success. The framework also allows us to compare outcomes across ICO financing and conventional financing methods.

Our results show that ICOs can have beneficial economic properties when compared with conventional financing strategies. All forms of financing we consider, including ICOs, can be inefficient. However, for certain projects, ICO financing generates a higher net present value than conventional modes of financing and is sometimes the only profitable form of financing. Crucial to this is the fact that the return to token investors under an ICO is based on the sales revenue of a project rather than profits.

Our analysis also reveals two potential drawbacks of ICOs. First, there is an upper limit on the fraction of future sales that can be shared with outside investors. Such a constraint is less likely to be binding for platform-like projects, where total sales revenue on the platform can be high, while the platform-owner takes only a small cut of the total sales by facilitating the activity on the platform. Second, there is the risk of token investors trying to increase their payoffs by cornering the market for tokens. Token ownership needs to be sufficiently widely dispersed to avoid such market manipulation.

Finally, our results show how the tokens issued in an ICO can become valuable without the start-up explicitly specifying how much value each token represents, as is the case in crowdfunding-like ICO schemes where a token represents a unit of output. In equilibrium, the tokens derive value from the mere fact that the start-up may create future transactional demand for the tokens. When ICOs first broke onto the scene, this contributed to the perception that ICOs allowed companies to obtain "money for nothing," because it allowed start-ups to raise funds without giving away ownership in the company. Our results debunk this notion by showing that the commitment to accept the tokens as the sole means of payment is in fact costly to both the start-up and its customers. As a result, ICO funding generates no additional value beyond a better alignment between the incentives of the entrepreneur and the interests of outside investors. 


\section{Introduction}

Two common methods of obtaining external funds for start-ups are debt contracts and selling an ownership share. It is well known from the literature that both methods may result in a principal-agent problem because the interests of an entrepreneur are not perfectly aligned with those of investors. Principal-agent problems may lead to suboptimal decisions by the entrepreneur after a start-up is initiated. They may also prevent valuable projects from being initiated in the first place if anticipated principal-agent problems are too severe and prevent the entrepreneur from being able to raise funds.

Initial coin offerings (or ICOs) are a relatively new mode of financing start-ups that involve the sale of coins (more accurately, digital tokens on a distributed ledger platform such as Ethereum) that enable the holder to access a service, obtain goods or share in the earnings of a project initiated by the entrepreneur. ${ }^{1}$ Despite confusion over what ICOs represent and how they would ultimately be viewed by regulators, ICOs surged in popularity throughout 2017 and into the second quarter of 2018 until increased regulatory pressure, instances of fraud $^{2}$ and poor performance statistics led to a sharp decline in both the origination and completion of ICOs in the second half of $2018 .{ }^{3}$ While the hype surrounding ICOs seems to have faded, the question remains as to whether ICOs should be dismissed as a passing fad or whether they represent an innovative funding structure that has the potential to solve an economic problem.

\footnotetext{
${ }^{1}$ In one extreme case the issuer made no promises related to the coins other than that they could be held and traded. See https://uetoken.com/.

${ }^{2}$ The largest ICO scam to date is from the Vietnamese firm Modern Tech Corporation, which issued two cryptocurrencies, Pincoin and iFan. This firm allegedly raised more than 650 million USD from over 30,000 investors and then disappeared (Reuters, 2018). Heightened awareness of fraud in the ICO market is exemplified in the SEC's creation of the website https://www.howeycoins.com/, which advertised a fake ICO called HoweyCoin and leads potential investors to an educational website on the risks of investing in ICOs (SEC, 2018).

${ }^{3}$ Data from www.icorating.com shows that the number of proposed ICOs increased steadily throughout 2017 from 5 in January to 195 in December (for a yearly total of 780). The number of proposals peaked at 275 in June of 2018. While the numbers of proposals remained high during the rest of 2018 (monthly totals were all higher than 150), the value raised fell sharply from a peak of 1.9 billion USD in May 2018 to less than 200 million USD in December 2018. A study by Ernst \& Young (2018) found that $86 \%$ of the leading ICOs that were listed on an exchange in 2017 traded below their initial listing price in the first half of 2018 and the value of the portfolio of these ICOs was down by $66 \%$.
} 
To address this question we focus on how raising external funds using ICOs affects the incentive structure of an entrepreneur and hence the ultimate success of projects that are financed in this new way. We provide a theoretical model in which an entrepreneur can undertake a project by making an initial investment and then must decide whether or not to exert effort to reduce costs. The project of the entrepreneur can involve either the production of products or services or the development of a platform that others can use to sell their products and services. The entrepreneur lacks the resources to finance the project, but can raise funds in the debt market, the venture capital market or the ICO market. When choosing to finance the project with an ICO, the entrepreneur raises funds by issuing coins in the form of digital tokens and selling some or all of these coins to external investors. The entrepreneur commits to accepting the issued coins as the only means of payment for goods and services offered by herself or others on the platform, and commits to not issuing any additional coins beyond the pre-committed amount.

The effort of the entrepreneur cannot be directly observed by investors; hence, a principalagent problem arises in which the incentives of the entrepreneur to exert effort may not be aligned with those of an investor. We examine how financing the initial investment through an ICO changes the incentives of the entrepreneur relative to debt and venture capital financing. We keep all other aspects of the funding market the same. Our results show that, depending on the characteristics of the start-up, an ICO may result in a better or worse alignment of the incentives of the entrepreneur and the interests of the investors compared with conventional modes of financing. In some cases, outcomes may be strictly improved by using an ICO. These results are derived in a framework in which all funding markets are perfectly competitive and there are no institutional differences between markets. In other words, benefits of ICO financing can arise without assuming a reduced regulatory burden, lower transaction costs or a better revelation of product quality through the "wisdom of the crowd." 4

\footnotetext{
${ }^{4}$ See the discussion of the related literature in the next section.
} 
Each mode of financing may produce different incentives for the entrepreneur to initiate the project or to exert effort to reduce costs. Financing in the venture capital market results in generally weaker incentives for the entrepreneur to exert effort, because the entrepreneur has to share the - potentially - higher profits as a result of exerting effort with external shareholders; see Jensen and Meckling (1976). Debt financing is characterized by a classical debt overhang problem à la Myers (1977), where the incentives of the entrepreneur are not distorted when good outcomes occur, but the entrepreneur has little incentive to exert effort in poor outcomes because the proceeds will be used to repay the debt.

ICOs may distort the incentives of an entrepreneur, but in a different manner. ICOs introduce the possibility that the entrepreneur will choose to default on its commitment to accept issued coins on the platform when the cost of keeping the commitment exceeds the value of the platform. The option to default on its commitment can distort the incentives of the entrepreneur to exert effort and can lead to inefficiencies because abandoning the commitment allows the entrepreneur to pass on some of the costs of operating the platform to the investors, therefore reducing the incentives to exert effort. Interestingly, in cases where operating the platform is sufficiently profitable, the entrepreneur always keeps its commitment and the incentives to exert effort are the same as if financing was not required. In this situation, the ICO may dominate both debt and venture capital financing in terms of efficiency. Moreover, some projects that would not occur with debt or venture capital because of incentive problems may be feasible with ICOs.

Our model reveals two aspects of ICO financing that are not present in conventional modes of financing and may limit its effectiveness. First, the amount that can be raised using an ICO is limited to a certain share of the future sales revenue. ${ }^{5}$ Our results show that this amount could be less than the amount required for the initial investment even if the net present value of the project is positive. Therefore, it may occur that certain projects with a positive net present value cannot be financed with an ICO. Such a situation is more

\footnotetext{
${ }^{5}$ Catalini and Gans (2018) identify a similar constraint using a different approach.
} 
likely to occur when the project has a relatively high gross margin, i.e., relatively high profits compared with sales revenue. In the context where the project of the entrepreneur involves developing a platform, the limit is determined by total sales on the platform rather than by the platform margin. Therefore, the upper limit on the amount that can be raised with an ICO is less likely to be a limiting factor for projects where the platform owner takes a small cut of the total sales on the platform.

Second, unless token ownership is sufficiently widely dispersed, the market for tokens is prone to manipulation. Our model shows that it may be profitable for external investors with sufficiently large blocks of tokens to corner the market. By initially withholding tokens from the market, they effectively reduce the supply of tokens, which drives up the equilibrium token price for a given amount of sales revenue on the platform. As a consequence, block investors may be able to sell a share of their token holdings at an initially higher price, which allows them to grab a disproportionately large share of the sales revenue from the project. Such market manipulation is particularly problematic in the context of the ICO market because it reduces the profitability of the project to the entrepreneur. We derive sufficient conditions under which such an outcome does not occur. These boil down to a relatively weak condition of sufficiently widely dispersed ownership of tokens. In practice, such a condition may be hard to monitor or enforce in a market that functions mainly on a pseudonymous basis. Market manipulation is less of a concern when the amount raised is sufficiently low, such that the entrepreneur is able to retain a substantial share of the tokens and sell those on the token market during the operational stage of the project.

Finally, our results undermine the notion that funds raised through an ICO represent "money for nothing." The notion arises because the entrepreneur sells no ownership share of the company, nor promises any debt payment to investors, and only commits to accepting otherwise worthless tokens as a means of payment. The fallacy in the "money for nothing" notion is that the commitment to accept tokens as the sole means of payment is perceived as costless to both the owner and the users of the platform. This perception is incorrect because 
it ignores the fact that it forces the users and the owner of the platform to hold the tokens over the lifetime of the platform, which is costly in terms of the time value of money due to the opportunity cost of capital. This reduces the value of the platform. Our results show that the difference in the value of the platform with and without the commitment to accept only tokens reflects exactly the amount at which token investors may ultimately liquidate their holdings. In summary, the ICO leads to a redistribution of cash flows from the project to investors and does not generate any additional value beyond that which may arise from a better alignment of incentives.

\section{Related Literature}

The tokens issued during an ICO in our model act as a privately issued digital currency for the products and services on the platform developed by the entrepreneur. The early theoretical models of Bolt and Van Oordt (forthcoming), Garratt and Wallace (2018) and Athey et al. (2016) explore the determinants of the exchange rate of privately issued digital currencies. A common result in these models is that the current value of such currencies depends on the potential future transactional usage. In anticipation of this, investors may rationally choose to hoard these currencies, which drives up the current exchange rate even before widespread transactional usage emerges. Entrepreneurs rely on this mechanism when opting for an ICO as a mode of financing for start-ups.

Our work contributes to a brand-new theoretical literature on ICO financing. Part of this literature attributes the potential usefulness of ICOs to informational and diversification advantages. Catalini and Gans (2018) show that the valuation of tokens in the ICO market may reveal important information about how customers value their products and services. The same information is not revealed when raising venture capital. Chod and Lyandres (2018) show that ICOs may provide entrepreneurs with better financing options in an environment with risk-averse agents where the ICO market has more investors with smaller 
shares, while venture capitalists are under-diversified and bear the idiosyncratic risk of the project.

Another suggested role for ICOs is to facilitate coordination in applications with network effects. Li and Mann (2018) show that ICOs as a mode of financing can help to avoid coordination failures. In their model, tokens act as vouchers that can be used to purchase services on a platform from other users against a fixed rate. They utilize the forward induction argument of Govindan and Wilson (2009) to eliminate inefficient equilibria where users do not connect to the platform because of the unknown presence of others. Since tokens are useless outside the platform, users have no reason to buy them unless they plan to connect to the platform. Hence, the past sale of tokens provides a signal to potential service providers, which ensures their presence on the platform. In a similar vein, Bakos and Hałaburda (2018) and Cong et al. (2018) derive models where an ICO is used to finance a platform with network effects. In these models, the ICO allows early adopters, who also hold tokens, to benefit from platform growth as their tokens appreciate. Bakos and Hałaburda (2018) derive conditions under which the network would issue tokens rather than providing the traditional user subsidy to overcome the coordination problem. Cong et al. (2018) derive a dynamic asset pricing model of tokens, where the ICO model can help accelerate platform adoption by paying a "dividend" in the form of token appreciation that partly internalizes the user-base externality.

Our goal is to evaluate the impact of ICO financing on entrepreneurial incentives while maintaining the same (comparable) market structure. We do not assume any informational or diversification advantage of the ICO market over the venture capital market or debt market. Moreover, our results are not driven by coordination problems or network effects. These are all valid justifications for ICO financing, and they are complementary to our story, but our analysis shows they are not necessary for ICO financing to dominate.

Some papers consider ICO models in which each issued token is assumed to represent a voucher for a given amount of output that is sold to consumers in advance (analogous 
to crowdfunding in the model of Strausz, 2017). Malinova and Park (2018) show that such financing can induce over- or underproduction in a context where the entrepreneur has market power. Lee and Parlour (2018) argue that voucher financing differs from bank funding in that consumers incorporate the impact of the project on their consumer surplus. The tokens in our model endogenously derive monetary value from the transactional demand created by the entrepreneur's commitment to accept the tokens as the only means of payment, without explicit specification of how much output each token represents.

Before proceeding to the analysis we would also like to point out that there is a rapidly expanding empirical literature on ICOs. Hu et al. (2018), Dittmar and Wu (2018), Benedetti and Kostovetsky (2018) and Bianchi and Dickerson (2018) study factors that affect the returns of investments in token markets. Lee et al. (2018) and De Jong et al. (2018) study the determinants of successful attempts to raise funds with an ICO. Howell et al. (2018) document factors that affect the liquidity and trading volumes of tokens in secondary markets.

\section{Model}

Consider the situation where an entrepreneur owns the unique knowledge to start a project that creates a platform for electronic commerce with a potentially positive net present value. ${ }^{6}$ The project consists of a development stage and an operational stage of the platform. The development stage consists of two periods, and the operational stage consists of an infinite number of periods (Figure 1). The positive risk-free interest rate is denoted by $r$.

During the first period of the development stage, which we call $t=0$, the entrepreneur seeks to raise an initial investment outlay $I_{0}>0$. At that time, due to uncertain demand, nobody (including the entrepreneur) knows how much revenue the platform will generate during the infinitely lasting operational stage, if the platform is launched. More precisely, each period after the launch, customers and retailers meet on the platform to buy and offer

\footnotetext{
${ }^{6}$ Real-world examples include proposed decentralized platforms for exchanging photographic output and services (KodakOne), music (Voise) or data storage (Filecoin).
} 
units of products or services. Retailers elastically supply units to customers on the platform at some price, $p_{s} \geq 0$. The per-period quantity of products or services that can be sold to customers on the platform, who value the product at price $p$, is determined by the outcome of the random variable $\tilde{s}$. We assume $\tilde{s}$ follows a probability distribution function $F$. The special case where $p_{s}=0$ corresponds to the situation where the project does not involve the development of a platform, but instead involves the more familiar setting where the entrepreneur produces and sells certain goods or services.

After the project is funded in period $t=0$, it advances to the second period of the development stage $(t=1)$, and the realized value of $\tilde{s}$ becomes known to all participants in the market. Beyond the initial investment outlay, no further investment is required to advance the project to the operational stage. However, the technology developed for the platform may become more cost-efficient if the entrepreneur exerts additional effort at a personal (non-pecuniary) cost $\bar{e}$. Specifically, the per-period cost of operating the platform during the operational stage depends on a random cost $\tilde{c}(e)$, where $\tilde{c}(0)=c_{H}$ with probability 1 , and $\tilde{c}(\bar{e})$ equals $c_{L}$ with probability $\gamma$ and $c_{H}$ with probability $1-\gamma$, where $0<c_{L}<c_{H}$. The effort expenditure $e \in\{0, \bar{e}\}$ is not directly observable, and, hence, $\bar{e}$ cannot be reimbursed or incorporated into an income statement and so cannot be part of the financing arrangement.

At $t=2$, the project enters the operational stage. At the start of this stage, the platform is launched for an infinite number of periods, or it is abandoned. During each period of the operational stage, the entrepreneur can charge a margin $m_{t}$ to retailers per unit sold on the platform. Given a realization $s$ of $\tilde{s}$, and provided that $p \geq p_{s}+m_{t}$, the platform will generate per-period sales revenue of $s\left(p_{s}+m_{t}\right)$, with $s p_{s}$ going to the retailers and $s m_{t}$ going to the entrepreneur for running the platform. From the market structure, it is not difficult to see that platform profit will be maximized by setting $m_{t}=m^{*}=p-p_{s}$ for any $t$. The entrepreneur not only maximizes the platform profit by choosing $m_{t}=m^{*}$, but also captures the total surplus. Given a constant margin $m$, the per-period cash flow from the project from $t=2$ onward equals $s(m-c(e))$, and the $t=2$ present value of the project 
Figure 1: Overview of the timing of decisions by the entrepreneur in the model

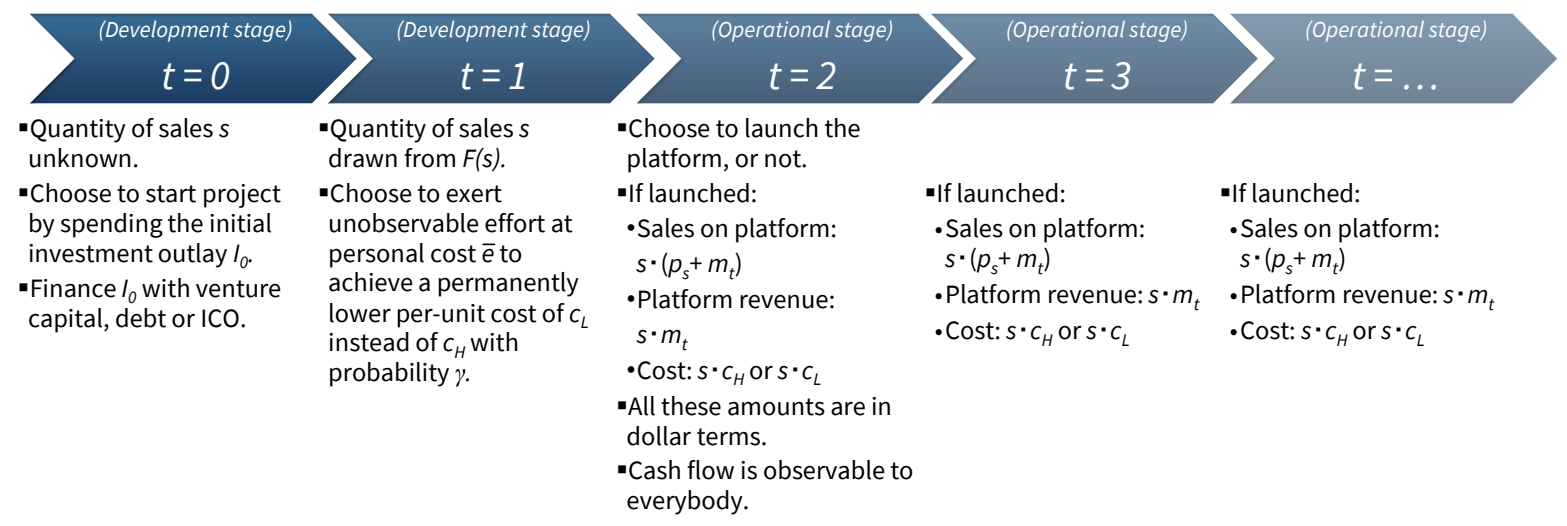

equals

$$
P V_{2}(s, c, m)=(1+r) P V_{1}(s, c, m)=\frac{1+r}{r} \max \{s(m-c(e)), 0\} .
$$

It is assumed that the cash flow from the project is verifiable for market participants at $t=2$. Consequently, the cost-efficiency of the platform will be known to all market participants at $t=2$. At this point, the stakeholders' continuing to own the venture is equivalent to selling the venture in a competitive capital market.

Equation (1) implies that it is optimal to launch the platform at the start of the operational stage whenever $\tilde{c}(e) \leq m^{*}=p-p_{s}$. There are two scenarios under which the initiation of the project at $t=0$ leads to the launch of the platform at $t=2$ : if $c_{L}<c_{H} \leq m^{*}$, then the platform is launched regardless of whether effort is successful, and if $c_{L} \leq m^{*}<c_{H}$, then the platform is launched only if $e=\bar{e}$ and effort is successful. Either case requires $c_{L} \leq m^{*}$, which is assumed going forward.

Suppose the project is initiated at $t=0$. We seek to understand under what financing arrangements the entrepreneur will undertake the efficient level of effort. If the platform will be launched regardless of whether successful effort occurs, i.e., if $c_{H} \leq m^{*}$, then it follows from equation (1) that efficiency requires the entrepreneur to exert effort whenever $\bar{e}<\gamma s\left(c_{H}-c_{L}\right) / r$, where $1 / r$ reflects the present value at $t=1$ of a per-period single dollar of cost savings. Alternatively, if the platform will be launched only when successful effort 
occurs, i.e., if $c_{H}>m^{*}$, then efficiency requires that the entrepreneur exert effort whenever $\bar{e}<\gamma s\left(m^{*}-c_{L}\right) / r$, where $m^{*}-c_{L}$ reflects the net margin for products sold on the platform that will be launched only when effort is successful. In summary, after initiating the project, efficiency requires the entrepreneur to exert effort whenever the realization of $\tilde{s}$ exceeds the threshold

$$
s^{*}=\frac{\bar{e} r / \gamma}{\min \left\{c_{H}, m^{*}\right\}-c_{L}} .
$$

Whether it is optimal for the entrepreneur to exert effort for all realizations of $s \geq s^{*}$ will depend on the financing choice $J$. In particular, in order for the entrepreneur to exert effort, the realization of $\tilde{s}$ needs to exceed some threshold $s^{J}$ that will depend on the financing choice $J$, which could be different from $s^{*}$. Below, we compare multiple ways in which the entrepreneur could finance the development stage of the project, and discuss the desirability of the outcomes. In addition to standard forms of debt or equity financing, we consider an ICO.

\subsection{Valuation of the project}

The value of the project after the investment outlay at $t=0$ can be decomposed into the hypothetical value that would be realized if the entrepreneur does not exert effort, $V_{0}^{H C}$, and the expected increase in value that results from the entrepreneur choosing to exert effort, $W_{0}\left(s^{J}\right)$. Specifically, we can write

$$
V_{0}\left(s^{J}\right)=V_{0}^{H C}+W_{0}\left(s^{J}\right)
$$

where $s^{J}$ denotes the threshold for exerting effort, which depends on the financing choice $J$.

Let $x(s)$ denote the stochastic discount factor from $t=0$ to $t=1$, i.e., the $t=0$ present value of a dollar payoff at $t=1$ that occurs only in state $s$ divided by the probability that 
state $s$ materializes. ${ }^{7}$ The $t=0$ present value of the cash flows from the project, assuming that the entrepreneur does not exert effort, equals

$$
V_{0}^{H C}=\int x(s) P V_{1}\left(s, c_{H}, m^{*}\right) d F(s)
$$

where the integral sums the present value of the project with high production costs for all states. The increase in the $t=0$ present value derived from the entrepreneur choosing to exert effort equals

$$
W_{0}\left(s^{J}\right)=\frac{\gamma}{r} \int_{s^{J}}^{\infty} x(s)\left[s\left(\min \left\{c_{H}, m^{*}\right\}-c_{L}\right)\right] d F(s),
$$

where the integrals sum the per-period benefit of effort for all states in which effort will occur, i.e., the states where $s^{J}<s$.

\subsubsection{Net present value of the project under financing choice $J$}

Let

$$
E^{J}(e)=\int_{s^{J}}^{\infty} x(s) \bar{e} d F(s)
$$

denote the expected value of $e$ conditional on financing choice $J$. The net present value of the project, including the cost of effort to the entrepreneur under financing choice $J$, is then given as

$$
N P V^{J}=V_{0}\left(s^{J}\right)-I_{0}-E^{J}(e)
$$

Notice that in our set-up, since all of the surplus is captured by the platform provider, the net present value of the project to the entrepreneur is the same as the total surplus generated by the project.

\footnotetext{
${ }^{7}$ Our notation assumes that the discount factor from $t=1$ to $t=2$ is independent of whether effort, if it were exerted, is successful or not. Dropping this assumption would add complexity without significant benefits: It would make the decision of the entrepreneur to exert effort depend on a risk-neutral probability of success $\gamma^{Q}$ which is the product of the probability $q$ and the ratio of the conditional on $s$ relative state-prices of the 'success-state' and the 'non-success state'.
} 


\section{$3.2 \quad$ Deep-pocketed entrepreneur}

As a benchmark, suppose the entrepreneur has deep pockets, meaning the entrepreneur does not require any additional capital to finance the project. The deep-pocketed entrepreneur makes the three sequential decisions summarized in Figure 1: whether to invest at $t=0$, whether to exert effort at $t=1$, and whether to launch the platform and what margin to charge from $t=2$ onward.

We consider that last decision regarding the platform launch first. The deep-pocketed entrepreneur will choose to launch the platform whenever $P V_{2}\left(s, c, m^{*}\right)$ in equation (1) is positive. This always holds true if $c_{H} \leq m^{*}$, and only when effort is successful if $c_{H}>m^{*}$.

We now turn to the decision to exert effort. The deep-pocketed entrepreneur is the only claimant to the cash flows from the project, so the entire increase in the present value of the project from exerting effort will accrue to the entrepreneur. Hence, it will be optimal for the deep-pocketed entrepreneur to exert effort whenever the expected benefit of effort, which is given by $\gamma\left[P V_{1}\left(s, c_{L}, m^{*}\right)-P V_{1}\left(s, c_{H}, m^{*}\right)\right]$, exceeds the cost $\bar{e}$. This holds true for any $s \geq s^{D P}$, where

$$
s^{D P}=s^{*} .
$$

Lastly, we turn to the decision to invest. To make it profitable to start the project, it is necessary that the value of the venture be sufficiently high to cover the initial investment in the early development stage. Therefore, it is optimal to initiate the project if and only if

the value of the venture $V_{0}\left(s^{D P}\right)$ exceeds the initial investment outlay $I_{0}$ and the expected cost of effort $E^{D P}(e)$. This is true when the net present value $N P V^{D P}$ defined in equation (7) is positive.

The deep-pocketed entrepreneur is the efficient benchmark, because it corresponds to maximizing the net present value in equation (7), which also corresponds to maximizing the total surplus. There are no distortions under the solution for the deep-pocketed entrepreneur 
because the entrepreneur bears the full cost and benefits of exerting effort and initiating the project.

\section{Conventional Modes of Financing}

Suppose that the entrepreneur needs to attract financing for the initial investment outlay $I_{0}$. Before exploring the implications of financing the project via an ICO, we look at two conventional models of financing: debt and equity.

\subsection{Debt financing}

Debt financing gives lenders the first claim on the value of the project at $t=2$ up to the promised amount, while the entrepreneur receives the residual value of the project. If the venture is insolvent at $t=2$, then the lenders take hold of the project. Suppose that lenders negotiate some promised repayment $D>0$ at $t=2$ in return for providing funds to the entrepreneur at $t=0$.

In this situation, the decision to launch the platform at $t=2$ is the same as in the case of the entrepreneur with deep pockets. If the value of the launched platform is positive and exceeds the negotiated payment $D$, then the entrepreneur will optimally choose to launch it and collect the residual value of the project. If the value of the launched platform is positive but less than the negotiated payment $D$, then the venture is insolvent and the lenders will take hold of the project and launch it themselves because the value of the venture is positive.

The decision to exert effort is complicated by the fact that part of the expected benefits to exerting effort may be used to repay the lenders; this is the so-called debt overhang problem. The benefit to the entrepreneur of exerting effort with debt financing equals

$$
\gamma\left[\max \left\{P V_{1}\left(s, c_{L}, m^{*}\right)-\frac{D}{(1+r)}, 0\right\}-\max \left\{P V_{1}\left(s, c_{H}, m^{*}\right)-\frac{D}{(1+r)}, 0\right\}\right] .
$$


The entrepreneur optimally chooses to exert effort whenever this benefit exceeds the cost of effort. From equation (9), we have that the entrepreneur will exert effort whenever $s>$ $s^{D F}(D, s)$, where

$$
s^{D F}(D, s)=\frac{\bar{e} r / \gamma}{\min \left\{c_{H}, m^{*}-\frac{r D}{s(1+r)}\right\}-c_{L}}
$$

for any $s>0$. Comparing equations (2) and (10) yields $s^{D F}(D, s) \geq s^{*}=s^{D P}$ for any $s>0$. In cases where the inequality is strict, effort occurs for a smaller set of realizations of $\tilde{s}$ than with the deep-pocketed entrepreneur.

Whether a potential debt overhang problem occurs depends on whether the value of the venture without successful effort is insufficient to repay the debt in full. From equations (2) and (10), we have that the inequality $s^{D F}(D, s) \geq s^{*}$ is strict if and only if $m^{*}-r D /[s(1+r)]<c_{H}$. This is equivalent to the condition: $D>P V_{2}\left(s, c_{H}, m^{*}\right)$, i.e., the promised debt repayment exceeds the value of the venture without successful effort. In this situation, lenders benefit from the entrepreneur exerting effort because successful effort is necessary to repay the debt in full. This holds true whenever $s$ is smaller than the threshold for default without successful effort:

$$
s^{\text {DefRisk }}(D)= \begin{cases}\frac{D r /(1+r)}{m^{*}-c_{H}} & \text { if } m^{*}>c_{H} \\ +\infty & \text { otherwise }\end{cases}
$$

When $s$ is larger than the above threshold, lenders do not benefit from the entrepreneur exerting effort.

Using the expression in (11), we can rewrite equation (10) as

$$
s^{D F}(D)= \begin{cases}\frac{\bar{e} r / \gamma+r D /(1+r)}{m^{*}-c_{L}} & s<s^{\operatorname{DefRisk}}(D) \\ s^{*} & \text { if } s \geq s^{\operatorname{DefRisk}}(D) .\end{cases}
$$


Note that $D$, discounted back to $t=1$, enters the equation for $s^{D F}(D)$ in a somewhat similar manner as the cost of effort when $s<s^{\text {DefRisk }}(D)$. It is caused by the fact that the entrepreneur will treat the future debt repayment as an additional "cost" of successful effort when the debt overhang problem occurs, while it would be socially optimal if the investment financed with the debt were treated as a sunk cost.

If the project is entirely financed with debt, then the entrepreneur sets $D$ equal to

$$
D^{*}=\left\{\min \{D\}: D_{0}(D) \geq I_{0}\right\}
$$

where $D_{0}(D)$, the value of the debt $D$ at $t=0$, is given by

$$
\begin{aligned}
D_{0}(D)= & \int_{s^{D}(D)}^{\infty} x(s)\left[\gamma D+(1-\gamma) \min \left\{P V_{1}\left(s, c_{H}, m^{*}\right), \frac{D}{1+r}\right\}\right] d F(s)+ \\
& \int_{0}^{s^{D}(D)} x(s) \min \left\{P V_{1}\left(s, c_{H}, m^{*}\right), \frac{D}{1+r}\right\} d F(s) .
\end{aligned}
$$

In order for the project to proceed, there must exist a $D$ satisfying (13). If there is no $D$ satisfying (13), then the entrepreneur does not initiate the project.

\subsection{Venture capital}

Suppose the entrepreneur raises funds at $t=0$ in the venture capital market. Investors in this market obtain some equity share $0<\omega \leq 1$ in the project in return for providing funds to the venture of the entrepreneur at $t=0$.

In this situation, the decision to launch the platform at $t=2$ is the same as in the case of deep pockets (scaling things down by $1-\omega$ does not change whether launching the platform is profitable). However, the decision to exert effort is affected by the fact that part of the expected returns to exerting effort go to the in-

vestor. The $t=1$ present value of the expected benefit to the entrepreneur of effort is $\gamma\left[P V_{1}\left(s, c_{L}, m^{*}\right)-P V_{1}\left(s, c_{H}, m^{*}\right)\right](1-\omega)$, and hence the expected net return to the en- 
trepreneur for their effort is $\gamma\left[P V_{1}\left(s, c_{L}, m^{*}\right)-P V_{1}\left(s, c_{H}, m^{*}\right)\right](1-\omega)-\bar{e}$. This means it is optimal for the entrepreneur to exert effort when raising funds in the venture capital market whenever $s \geq s^{V C}(\omega)$, where

$$
s^{V C}(\omega)=\frac{1}{1-\omega} \times \frac{\bar{e} r / \gamma}{\min \left\{c_{H}, m^{*}\right\}-c_{L}}=\frac{s^{*}}{1-\omega} .
$$

We now turn to the decision of the entrepreneur to expend $I_{0}$ to start the project at $t=0$. First, we have to establish what share $0<\omega<1$ of equity the entrepreneur must surrender to the investor in order to acquire $I_{0}$. If we assume the venture capital market is perfectly competitive and that the entire initial investment is financed by venture capital, then the entrepreneur sets the equity share of outside investors $\omega=\omega^{*}$, where

$$
\omega^{*}=\min \left\{\omega: \omega \times V_{0}^{V C}\left(s^{V C}(\omega)\right) \geq I_{0}\right\} .
$$

The condition for investment to occur is that the solution to equation (16) satisfies $0 \leq \omega^{*} \leq 1$.

\subsection{Efficiency of conventional modes of financing}

The deep-pocketed solution is the efficient benchmark in that the project is initiated and effort is exerted if and only if these actions increase the net present value of the project to the entrepreneur, which in this framework is equivalent to increasing social welfare. In evaluating conventional financing schemes, we ask two questions. One, is the project initiated as often as efficiency requires? Two, is the value generated by the project under each financing scheme as large as it is under the deep-pocketed solution? The only way to answer the first question is to specify a probability distribution function $F$ and other parameter values, which we do collectively for all financing models, including an ICO, in Section 6. We can address the second question here. The deep-pocketed solution is efficient, so no alternative financing method can improve upon this. Moreover, under alternative financing schemes, 
the entrepreneur does not completely internalize the benefits of exerting effort. Hence, in some instances, outcomes with conventional modes of financing will be inefficient.

Denote a vector of parameters for our model by $\lambda=\left(c_{L}, c_{H}, \gamma, p, p_{S}, \bar{e}, I_{0}, r\right)$ and denote the set of parameter vectors by $\Lambda \subset \mathbb{R}_{++}^{8}$. For any $\lambda \in \Lambda$ and any probability distribution $F$, we have the following two results:

Claim $1 N P V^{D F} \leq N P V^{D P}$. In some cases, the inequality is strict.

Proof. The inequality holds true since the deep-pocketed solution is efficient. In cases where the project is initiated only when the entrepreneur has deep pockets but not when the entrepreneur needs to rely on debt financing, the net present value will be positive instead of zero and, hence, $N P V^{D P}>N P V^{D F}=0$. In cases where the project is initiated with both debt financing and deep pockets, effort is exerted more often when the entrepreneur has deep pockets, since $s^{D F}(D, s) \geq s^{*}=s^{D P}$ for any $s>0$ from equation (10). In particular, the threshold level for exerting effort with debt financing is strictly larger than $s^{*}$ whenever the value of the project without successful effort is insufficient to repay the debt, i.e., whenever $s<s^{\operatorname{DefRisk}}(D)$ from equation (11). Altogether, we have that $N P V^{D P}>N P V^{D F}$ whenever $N P V^{D P}>0$ and the support of $F(s)$ contains at least one set of positive measure in the interval $\left[s^{*}, s^{D F}\right)$.

Claim $2 N P V^{V C} \leq N P V^{D P}$. In some cases, the inequality is strict.

Proof. Trivially, the inequality holds true since the deep-pocketed solution is efficient. Moreover, in the cases where the project is initiated under the deep-pocketed solution and not under venture capital financing, the payoff to the entrepreneur is positive instead of zero. In cases where the project is initiated under venture capital financing and with deep pockets, effort is exerted more often under deep pockets. The deep-pocketed entrepreneur exerts effort whenever it increases the net present value of the project. However, venture capital reduces the set of realizations of $\tilde{s}$ for which the entrepreneur exerts effort, regardless 
of what compensation the investors require in terms of the share of future revenues, since it follows directly from equation (15) that $s^{D P}=s^{*} \leq s^{V C}\left(\omega^{*}\right)$ for any $0<\omega<1$. The inequality is strict if and only if $N P V^{D P}>0$ and the support of $F(s)$ contains at least one set of positive measure in the interval $\left[s^{*}, s^{V C}\right)$.

\section{$5 \quad$ Initial Coin Offering}

\subsection{How it works}

As in the previous scenarios, the entrepreneur needs to acquire an initial investment of $I_{0}$ to fund the project at $t=0$. The entrepreneur does so by conducting an ICO in which it creates $M$ coins, of which it sells a fraction $\phi$ to investors at $t=0$. In order to achieve comparability with previous financing models, we assume that $\phi$ is defined so that at the equilibrium exchange rate, the value of the coins sold matches the amount of the investment required at $t=0$. The entrepreneur commits to selling the remaining coins, $(1-\phi) M$, at $t=2$.

At the time of the ICO, the sales revenue in each period on the platform depends on the realization of $\tilde{s}$, which is still uncertain. Nevertheless, the entrepreneur commits to accepting only the issued coins for sales from the venture and to not issuing additional coins beyond the pre-committed amount $M$. If the entrepreneur breaches any of its commitments, then the coin owners are assumed to take hold of the platform in a costless manner, as is the case with a breach of the debt contract. ${ }^{8}$

At $t=2$, the investors and the entrepreneur have the opportunity to sell their respective holdings of coins to consumers who are interested in purchasing the realized output of the

\footnotetext{
${ }^{8}$ This would require some type of legal enforcement that may not currently exist. This is part of the overall regulatory and legal uncertainty surrounding ICOs that needs to be resolved before they become mainstream. None of the claims or propositions established in this paper depend on this assumption. In particular, we could assume that the project is shut down when the entrepreneur defaults on its commitments. We select the assumption that the coin owners take hold of the platform when the entrepreneur defaults on its commitments because it is the closest to what happens when the debt contract is breached.
} 
project. We will establish conditions, which we will assume to hold, under which investors optimally choose to sell all of their holdings to customers on the platform at $t=2$. Customers do not contemplate holding coins for investment purposes. Rather, they spend all of the coins they acquire in a period on products or services offered on the platform in the same period..$^{9}$ When customers spend coins on the platform, part of the proceeds are distributed to the retailers, and part of the proceeds are distributed to the entrepreneur through its collection of the margin $m$. Hence, at the end of period 2, the coins spent by customers will be held by retailers and the entrepreneur, who sell them to customers at the beginning of period 3 . From $t=3$ onward, both retailers and the entrepreneur sell all of the coins they acquire to new customers who wish to buy products and services at the beginning of the following period. ${ }^{10}$

The ICO does not create an explicit debt for the entrepreneur, nor does it explicitly transfer any right to the cash flows from the project. However, keeping the commitments made in an ICO is not without economic cost to the entrepreneur. The magnitude of this economic cost is reflected in the difference in the cash flows from the project when using a conventional financing model and the cash flows from the project and token sales when the entrepreneur commits to allowing only payments with tokens for sales on the platform.

\subsection{Decision by token investors}

The entrepreneur commits to accepting only the issued coins for sales on the platform. This could lead to strategic decisions by token investors. For example, a monopolistic token investor could choose to withhold some of the coins from the market to liquidate his or her tokens at an initially higher exchange rate. Such an action would put downward pressure on the price of tokens once the investor liquidates the remainder of his or her coin holdings.

\footnotetext{
${ }^{9}$ Consumers have in principle the same incentives to hold coins as small investors. Subsection 5.2 shows that it is not optimal for small investors to hold tokens for investment purposes after $t=2$.

${ }^{10}$ For the results, it doesn't matter whether the entrepreneur and retailers resell the tokens to consumers in the next period (i.e., at $t=3$ for tokens received at $t=2$ ), or whether they directly resell the tokens at the end of the same period (i.e., at the end of $t=2$ for tokens received at $t=2$ ).
} 
Entrepreneurs and the retailers may be affected by such actions because they rely on selling tokens to potential customers in the next period to collect the proceeds from sales on the platform.

To determine conditions under which exchange rate manipulation does not occur, suppose that the amount of coins held by coin investor $i$ equals $H^{i}$ and let $h_{t}^{i}$ denote the amount of coins that investor $i$ sells to customers on the platform at $t=2,3, \ldots$ Let $h_{t}^{-i} \geq 0$ denote the amount that is sold by all other investors at time $t$. The equilibrium price, or exchange rate, of the coins at $t=2,3, \ldots$ must equal

$$
S_{t}=\frac{s p}{h_{t}^{i}+h_{t}^{-i}+W_{t-1}}
$$

where $W_{t-1}$ is the sum of the coins liquidated by investors in all previous periods plus the coins liquidated by the entrepreneur at $t=2$, i.e.,

$$
W_{t-1}=(1-\phi) M+\sum_{\tau=1}^{t-1}\left(h_{\tau}^{i}+h_{\tau}^{-i}\right)
$$

where $h_{1}^{i}+h_{1}^{-i}=0$.

The total revenue of coin investor $i$ from liquidating coins is given by

$$
\begin{aligned}
\pi_{i} & =\sum_{t=2}^{\infty} \frac{h_{t}^{i} S_{t}}{(1+r)^{t-1}} \\
& =s p \sum_{t=2}^{\infty} \frac{h_{t}^{i}}{(1+r)^{t-1}\left[h_{t}^{i}+h_{t}^{-i}+W_{t-1}\right]}
\end{aligned}
$$

The objective of coin investor $i$ is to maximize $\pi_{i}$ by optimally choosing $h_{t}^{i} \geq 0$ for $t=$ $2, \ldots, \infty$ for a given sequence of $h_{t}^{-i}$, subject to

$$
\sum_{t=2}^{\infty} h_{t}^{i} \leq H^{i}
$$


We now define a condition that ensures that the coin investor will not withhold coins from the market in the first period that the platform is launched, i.e., a sufficient condition that guarantees the coin investor will optimally choose $h_{2}^{i}=h^{i}$.

The Lagrangian for the coin investor's maximization program is

$$
\pi_{i}=\operatorname{sp} \sum_{t=2}^{\infty} \frac{h_{t}^{i}}{(1+r)^{t-1}\left[h_{t}^{i}+h_{t}^{-i}+W_{t-1}\right]}+\lambda\left[H^{i}-\sum_{t=2}^{\infty} h_{t}^{i} \cdot\right]
$$

Taking the partial derivative with respect to $h_{t}^{i}$ (note that $W_{t-1}$ includes the sum of all past $h_{t}^{i}$ ) and rewriting gives the following first-order condition:

$$
s p \frac{h_{t}^{-i}+W_{t-1}}{(1+r)^{t-1}\left[h_{t}^{i}+h_{t}^{-i}+W_{t-1}\right]^{2}}-s p \sum_{\tau=t+1}^{\infty} \frac{h_{\tau}^{i}}{(1+r)^{\tau-1}\left[h_{\tau}^{i}+h_{\tau}^{-i}+W_{\tau-1}\right]^{2}}-\lambda=0 .
$$

The first component of this equation is the marginal net revenue from selling additional coins in period $t$, and the second component is the marginal negative impact that selling additional coins in period $t$ has on future revenue because of a lower exchange rate in all future periods. A similar first-order condition, with nearly the same eternal sum, can be obtained by taking the derivative with respect to $h_{t+1}^{i}$. Taking the difference between the two first-order conditions results in these two eternal sums almost entirely cancelling each other out:

$$
\frac{h_{t}^{-i}+W_{t-1}}{(1+r)^{t-1}\left[h_{t}^{i}+h_{t}^{-i}+W_{t-1}\right]^{2}}-\frac{h_{t+1}^{i}}{(1+r)^{t}\left[h_{t+1}^{i}+h_{t+1}^{-i}+W_{t}\right]^{2}}=\frac{h_{t+1}^{-i}+W_{t}}{(1+r)^{t}\left[h_{t+1}^{i}+h_{t+1}^{-i}+W_{t}\right]^{2}}
$$

Rewriting gives

$$
(1+r)\left(h_{t}^{-i}+W_{t-1}\right)=\beta\left(h_{t}^{i}+h_{t}^{-i}+W_{t-1}\right),
$$

where

$$
\beta=\frac{h_{t}^{i}+h_{t}^{-i}+W_{t-1}}{h_{t+1}^{i}+h_{t+1}^{-i}+W_{t}}
$$


Note that since $W_{t}=h_{t}^{i}+h_{t}^{-i}+W_{t-1}$ and $h_{t+1}^{i}, h_{t+1}^{-i} \geq 0$, we must have $\beta \leq 1$. As a consequence, it must hold true that

$$
(1+r)\left(h_{t}^{-i}+W_{t-1}\right) \leq\left(h_{t}^{i}+h_{t}^{-i}+W_{t-1}\right)
$$

This gives a direct condition, that the optimal solution for the coin investor requires that the number of coins liquidated at time $t$ must exceed a certain number:

$$
h_{t}^{i} \geq r\left(h_{t}^{-i}+W_{t-1}\right)
$$

At $t=2$, the condition for the optimal solution simplifies to

$$
h_{2}^{i} \geq r h_{2}^{-i}+r(1-\phi) M
$$

Under the optimal strategy, the coin investor wishes to sell more coins than the product of the interest rate and the amount of coins sold by all other investors and the entrepreneur. Note, however, that $h_{2}^{i}$ is constrained in magnitude by $H^{i}$ because the investor cannot liquidate more coins than her initial coin holdings. Whenever this constraint is binding, the coin investor sells all her coins in the first period. A sufficient condition for this to occur is that the share of tokens held by each investor $i$ is sufficiently small:

$$
H^{i} \leq r(1-\phi) M+r h_{2}^{-i}
$$

In Appendix A, we provide examples of token ownership distributions under which the sufficient condition expressed in equation (22) is satisfied. The essential requirement is that token ownership must be sufficiently widely dispersed. In what follows, we focus on environments where this holds true, and hence investors sell all their coin holdings at $t=2$, the supply of tokens to consumers on the platform is $M$, and the exchange rate of the tokens 
for $\tilde{s}=s$ is

$$
S_{t}=\frac{s p}{M}, \text { for } t=2, \ldots, \infty
$$

When the entrepreneur keeps the commitment to accept the tokens as the sole means of payment, the entrepreneur and the investors will sell their combined holdings of tokens at $t=2$ for a total value $M S_{2}=s p$. This implies that, when the entrepreneur keeps the commitment, the payoff to token investors depends on future sales on the platform rather than future profits.

\subsection{Keeping the commitment under the ICO}

If the entrepreneur launches the platform, then the retailers would, in the absence of an ICO, receive a cash flow from sales in every period from $t=2$ onward. With an ICO, the retailers receive tokens at $t=2$ instead. They experience a cash inflow only once the coins are resold to consumers at $t=3$. The magnitude of this cash inflow will depend on the number of tokens they receive at $t=2$ and the price at which they can sell those tokens at $t=3$. The retailers require a $t=2$ cash inflow of at least $p_{s}$ for each unit sold; hence, they

will be willing to supply products if they earn in expectation at least $(1+r) p_{s}$ in terms of a $t=3$ cash inflow from selling tokens. It follows that, conditional on the investors liquidating all of their tokens at $t=2$, the profit-maximizing entrepreneur will set the margin equal to some infinitesimal amount below

$$
m_{t}^{I C O}=p-(1+r)\left(\mathbb{E} S_{t+1} / S_{t}\right) p_{s}=p-(1+r) p_{s}
$$

Table I shows the three main consequences of keeping the commitment to accept tokens as the sole means of payment on the platform. First, from period $t=3$ onward, the project earns the smaller margin in equation (24) on the platform (indicated in blue). Second, the project experiences a one-period delay in the cash inflows from sales on the platform (indicated in green). The $t=2$ present value of these two consequences combined, which 
Table I: Cash flow comparison

\begin{tabular}{|c|c|c|c|c|c|c|}
\hline Time & $t=0$ & $t=1$ & $t=2$ & $t=3$ & $t=4$ & $t=\ldots$ \\
\hline Deep Pockets & 0 & 0 & $+s\left(p-p_{s}\right)$ & $+s\left(p-p_{s}\right)$ & $+s\left(p-p_{s}\right)$ & $+s\left(p-p_{s}\right)$ \\
\hline $\mathrm{ICO}$ & $+\phi M S_{0}$ & 0 & $+(1-\phi) s p$ & $+s\left(p-(1+r) p_{s}\right)$ & $+s\left(p-(1+r) p_{s}\right)$ & $+s\left(p-(1+r) p_{s}\right)$ \\
\hline Difference & $+\phi M S_{0}$ & 0 & $+(1-\phi) s p-s\left(p-p_{s}\right)$ & $-r s p_{s}$ & $-r s p_{s}$ & $-r s p_{s}$ \\
\hline
\end{tabular}

Note: The first line of the table reports the cash flows from the project when it is financed with deep pockets. The second line of the table reports the cash flows from the project when it is financed with an ICO and the entrepreneur keeps the commitment to accept tokens as the sole means of payment. The symbols have the following meanings: $\phi$ is the share of tokens sold to investors, $M$ is the total number of tokens, $S_{0}$ is the price of the tokens at $t=0, s$ is the level of consumer demand, $p$ is the reservation price of consumers, $p_{s}$ is the minimum dollar price at which merchants are willing to supply their product on the platform and $r$ is the interest rate.

represents the total economic cost of keeping the commitment, equals

$$
\underbrace{s\left(p-p_{s}\right)}_{\text {Delay }}+\underbrace{\frac{r s p_{s}}{r}}_{\text {Smaller margin }}=s p .
$$

The third consequence of keeping the commitment to accept the tokens as the sole means of payment is that there is an additional $t=2$ cash inflow of $(1-\phi) s p$ from liquidating the retained share of the coins, $(1-\phi)$ (indicated in orange). Overall, the $t=2$ present value of the net change in revenues (from decreased cash flow and sales of retained tokens) that results from honoring the commitment equals $-\phi s p$.

When the entrepreneur does not honor the commitment to accept the tokens as the sole means of payment on the platform, the entrepreneur loses the project to the token investors (which would include herself if $\phi<1$ ). In this situation, the $t=2$ present value of the project to the entrepreneur equals $(1-\phi) P V_{2}\left(s, c, m^{*}\right)$. Therefore, it is optimal for the entrepreneur to keep the commitment whenever $P V_{2}\left(s, c, m^{*}\right)-\phi s p \geq(1-\phi) P V_{2}\left(s, c, m^{*}\right)$. As a result, the entrepreneur will choose to keep the commitment whenever $P V_{2}\left(s, c, m^{*}\right) \geq s p$. ${ }^{11}$

\footnotetext{
${ }^{11}$ Sometimes, ICOs are used to finance platforms that are claimed to require the users and providers of products and services on the platform to transact using only the issued tokens, without charging any additional margin on the platform. Note that, in such a situation, the commitment to accept the issued tokens as the sole means of payment on the platform is credible only for realizations $\tilde{c}(e)=0$.
} 


\subsection{Optimal strategy for the entrepreneur}

With ICO financing, the decision to launch the platform at $t=2$ is the same as before. The decision to exert effort depends on the payoff to the entrepreneur, which in turn depends on whether the entrepreneur will honor the commitment to accept the tokens as the sole means of payment. There are three possible scenarios. The first scenario arises when $P V_{2}\left(s, c_{H}, m^{*}\right) \geq s p$. In this scenario, the entrepreneur optimally chooses to honor the commitment to accept the tokens as the sole means of payment on the platform, regardless of whether effort is successful. This scenario holds true if $m^{*}-\operatorname{pr} /(1+r) \geq c_{H}$. In this situation, it is optimal for the entrepreneur to exert effort whenever $\gamma\left[\left(P V_{2}\left(s, c_{L}, m^{*}\right)-\phi s p\right)-\left(P V_{2}\left(s, c_{H}, m^{*}\right)-\phi s p\right)\right] \geq \bar{e}(1+r)$. No distortions occur and the entrepreneur mimics the efficient solution and exerts effort for any $s \geq s^{*}$.

The second scenario arises when $P V_{2}\left(s, c_{L}, m^{*}\right)<s p$. In this scenario, the entrepreneur optimally chooses to never honor the commitment to accept the tokens as the sole means of payment on the platform, even when effort is successful. This scenario holds true if $m^{*}-p r /(1+r)<c_{L}$. In this situation, the token investors simply receive a proportional ownership share when the platform is launched. The incentives of the entrepreneur will be comparable to those when the entrepreneur raises funds with venture capital, except that the ownership share of investors is now reflected by the token share $\phi$. The entrepreneur exerts effort whenever $\gamma(1-\phi)\left(P V_{1}\left(s, c_{L}, m^{*}\right)-\left(P V_{1}\left(s, c_{H}, m^{*}\right)\right) \geq \bar{e}\right.$, which is equivalent to the entrepreneur exerting effort for any $s \geq s^{V C}(\phi)$.

The third scenario arises when $P V_{2}\left(s, c_{H}, m^{*}\right)<s p \leq P V_{2}\left(s, c_{L}, m^{*}\right)$. In this scenario, the entrepreneur optimally chooses to honor the commitment when effort is exerted and is successful, but the entrepreneur does not honor the commitment when effort is not exerted or is not successful. This scenario holds true if $c_{L} \leq m^{*}-\operatorname{pr} /(1+$ $r)<c_{H}$. In this scenario, it is optimal for the entrepreneur to exert effort whenever $\gamma\left[\left(P V_{2}\left(s, c_{L}, m^{*}\right)-\phi s p\right)-(1-\phi) P V_{2}\left(s, c_{H}, m^{*}\right)\right] \geq \bar{e}(1+r)$. The entrepreneur exerts effort 
for any materialization of $\tilde{s}$ exceeding some threshold $s^{I C O+}(\phi)$, where

$$
s^{I C O+}(\phi)=\frac{\bar{e} r / \gamma}{\min \left\{c_{H}, m^{*}\right\}-c_{L}-\phi p r /(1+r)} \geq s^{*} .
$$

To summarize, the entrepreneur exerts effort for any states $s \geq s^{I C O}(\phi)$, where

$$
s^{I C O}(\phi)= \begin{cases}s^{*} & \text { if } c_{H} \leq m^{*}-p r /(1+r) \\ s^{I C O+}(\phi) & \text { if } c_{L} \leq m^{*}-p r /(1+r)<c_{H} \\ s^{V C}(\phi) & \text { otherwise. }\end{cases}
$$

Equation (27) shows how the incentives of the entrepreneur change in response to changes in the share of tokens sold to investors. The value of $s^{I C O+}(\phi)$ increases in the fraction of tokens sold to investors, $\phi$. In other words, the states of the world in which the entrepreneur exerts effort is larger when the entrepreneur retains a larger share of tokens during the development stage of the project and keeps the share of tokens sold to investors as small as possible.

The value of tokens sold at $t=0$ in perfectly competitive capital markets equals

$$
\begin{aligned}
& \quad I C O_{0}(\phi)= \\
& \quad \phi \int_{s^{I C O}(\phi)}^{\infty} x(s)\left[\gamma \min \left\{P V_{1}\left(s, c_{L}, m^{*}\right), \frac{s p}{1+r}\right\}+(1-\gamma) \min \left\{P V_{1}\left(s, c_{H}, m^{*}\right), \frac{s p}{1+r}\right\}\right] d F(s) \\
& +\phi \int_{0}^{s^{I C O}(\phi)} x(s)\left[\min \left\{P V_{1}\left(s, c_{H}, m^{*}\right), \frac{s p}{1+r}\right\}\right] d F(s) .
\end{aligned}
$$

The first component reflects the value of the tokens for realizations of $\tilde{s}$ where the entrepreneur exerts effort. The second component reflects the value of the tokens in the states where no effort occurs. Note that, given the decision to issue $M$ coins, the $t=0$ exchange rate, denoted $S_{0}$ in Table $\mathrm{I}$, is determined by the equation $I C O_{0}(\phi)=\phi M S_{0}$. The en- 
trepreneur optimally sets $\phi=\phi^{*}$, where

$$
\phi^{*}=\min \left\{\phi: I C O_{0}(\phi) \geq I_{0}\right\}
$$

The remaining share of the tokens $\left(1-\phi^{*}\right)$ are retained by the entrepreneur until the development stage is completed. The condition for investment to occur is that the solution to equation (29) satisfies $0 \leq \phi^{*} \leq 1$.

\subsection{Efficiency of ICO financing}

As in the case of conventional financing methods, financing through an ICO may disincentivize effort for some realizations of $\tilde{s}$. The following result holds for for any $\lambda \in \Lambda$ and any probability distribution $F$.

Claim $3 N P V^{I C O} \leq N P V^{D P}$. In some cases, the inequality is strict.

Proof. The inequality holds since the deep-pocketed solution is efficient. Moreover, in the cases where the project is initiated under the deep-pocketed solution and not under ICO financing, the payoff to the entrepreneur is positive instead of zero. In cases where the project is initiated under ICO financing and with deep pockets, effort is exerted more often under deep pockets, because the cut-off $s^{I C O}$ is weakly greater than the cut-off $s^{D P}=s^{*}$. The inequality is strict whenever $N P V^{D P}>0$ and the support of $F(s)$ contains at least one value on the interval $\left[s^{*}, s^{I C O}\right)$.

ICO financing is different from conventional financing in that the payoff to the outside investors depends on future sales rather than future profits (if the entrepreneur honors the commitment to accept the tokens as the only means of payment for the products or services on the platform). As a consequence, an ICO does not allow external investors to share in the benefits of effort when effort translates into cost savings rather than additional sales revenue. Potential inefficiencies in ICO financing arise for two reasons. The first reason is that the 
incentives of the entrepreneur are altered whenever the value of the tokens depends on realized cost savings. This can occur because lower costs may affect the production decision or because they may affect the decision to accept tokens as the sole means of payments on the platform. In this situation, token investors may benefit indirectly from the effort of the entrepreneur to achieve cost savings, meaning that the entrepreneur shares some of the benefits of exerting effort with external investors, which leads to weaker incentives for the entrepreneur. The second reason why an ICO can be inefficient is that the amount that can be raised is limited to the discounted expected value of one period of sales revenue on the platform. ${ }^{12}$ This amount could be less than the amount required for the initial investment even if the net present value of the project is positive. Therefore, certain projects that have a positive net present value cannot be financed with an ICO.

The following proposition summarizes this discussion by showing that the ICO is an efficient financing model whenever (1) the margin of the platform exceeds some threshold when it operates with a high marginal cost, and (2) the discounted value of expected sales revenue is sufficiently large compared with the initial investment.

Proposition 1 ICO financing is efficient whenever $c_{H} \leq m^{*}-p r /(1+r)$ and

$$
I_{0} \leq \int x(s) \frac{s p}{1+r} d F(s) .
$$

Proof. The proposition follows immediately from equation (1) and equations (27)-(29).

Analogous conditions can be derived for debt financing. In the case of equity financing, the sufficient conditions for efficiency depend on the distribution function $F$.

\footnotetext{
${ }^{12}$ See the conclusion for additional discussion on this point.
} 


\section{6 "Money for nothing" fallacy}

Our results refute the notion that funds raised through an ICO represent "money for nothing." The issuance of tokens in an ICO results in a redistribution of cash flows and does not generate any additional value, apart from the additional value created by a potential change in incentives. Given the entrepreneur's decision to accept only tokens, the agents acting on the platform are required to hold these tokens, which in our model are ultimately risk free. These agents are missing out on the interest that could be earned by holding an alternative risk-free asset at rate $r$. This opportunity cost is passed through, resulting in lower margins on the platform. There is also a delay in the cash flows generated by the platform, which has to be priced at the opportunity cost of capital. The present value of these costs reflects exactly the exchange value of the tokens.

This is summarized in the following proposition.

Proposition 2 The $t=2$ value of the coins when the entrepreneur honors the commitment to accept only the issued coins for sales on the platform equals the cost of honoring the commitment.

Proof. From (23) we know that the value of the coins when the entrepreneur honors the commitment is $s p$. The cost of honoring the commitment equals the reduction in the present value of the project as a consequence of honoring instead of breaking the commitment. From (25) we know that this reduction in present value is also $s p$.

Some ICOs were accompanied by wild speculations regarding the potential value of the tokens if the projects turned out to be successful. An alternative way of interpreting Proposition 2 is that it is a simple sanity check for the valuation of tokens. It shows that the commitment to accept the tokens as the only means of payment represents a real cost to the project, and that the level of the cost is reflected in the exchange value of tokens. This implies that a reasonable valuation of the tokens cannot exceed the hypothetical valuation of the project in the absence of the commitment to accept tokens as the sole means of payment 
on the platform (while holding the incentives of the entrepreneur to exert effort unchanged). If the opposite were to hold true, then the present value of the project after taking into account the cost to accept the tokens would be less than zero, and there would be no incentive to continue the project while keeping the commitment.

\section{Comparison Across Financing Schemes}

Comparison across financing schemes requires the specification of a probability distribution $F$ that characterizes the random variable $\tilde{s}$, which represents sales on the platform. In order to compute solutions under each financing model, we make the simplifying assumption that $F$ is discrete. Specifically, we assume $F$ is a discrete distribution that takes values $s_{H}$ with probability $\delta$ and $s_{L}$ with probability $(1-\delta)$ and we set $x\left(s_{L}\right)=x\left(s_{H}\right)=1 /(1+r)$.

The following result shows that any of the three funding alternatives we consider can be strictly preferred by the entrepreneur in certain circumstances.

Proposition 3 The following strict net present value relationships are possible:

1. $N P V^{I C O}>\max \left\{N P V^{D F}, N P V^{V C}\right\}>0$

2. $N P V^{D F}>\max \left\{N P V^{V C}, N P V^{I C O}\right\}>0$

3. $N P V^{V C}>\max \left\{N P V^{D F}, N P V^{I C O}\right\}>0$

Proof. Ranking 1 is obtained in example 1, which is described in Tables II and III, computed in Appendix B and illustrated in Figure 2. Rankings 2 and 3 are established by examples 2 and 3, respectively, from Tables II and III.

Proposition 3 confirms that each mode of financing can be preferred over the other modes in cases where at least one of the other modes of financing is profitable. Of particular interest is the fact that sometimes ICOs are the best mode of financing. This result is essential to our conclusion that ICOs are an innovation in financing with economic benefits. 
Equally relevant to our assessment of ICOs is the fact that sometimes only one form of financing is sufficiently profitable for the project to be initiated. Let $\Lambda^{J} \subset \Lambda$ denote the subset of parameter vectors for which $V_{0}\left(s^{J}\right)>I_{0}+E^{J}(e)$ - i.e., the net present value is positive - and hence the project will be initiated when mode $J$ of financing is used. Then we have:

Proposition 4 The following sets are non-empty: ${ }^{13}$

1. $\Lambda^{I C O}-\left(\Lambda^{V C} \cup \Lambda^{D F}\right)$

2. $\Lambda^{D F}-\left(\Lambda^{V C} \cup \Lambda^{I C O}\right)$

3. $\Lambda^{V C}-\left(\Lambda^{I C O} \cup \Lambda^{D F}\right)$

Proof. Non-emptiness of each of the sets is established by examples 4 through 6 , described in Tables II and III. Example 4 proves $\Lambda^{I C O}-\left(\Lambda^{V C} \cup \Lambda^{D F}\right) \neq \varnothing$. Example 5 proves $\Lambda^{D F}-\left(\Lambda^{V C} \cup \Lambda^{I C O}\right) \neq \varnothing$. Example 6 proves $\Lambda^{V C}-\left(\Lambda^{I C O} \cup \Lambda^{D F}\right) \neq \varnothing$.

Proposition 4 shows that each financing mode can be the only one that works for some projects. In particular, the non-emptiness of set 1 says that some projects can be initiated with ICO financing, but not with venture capital or debt financing. Entrepreneurs will not be able to successfully raise the funds necessary to initiate the project in any funding market besides the ICO market. In contrast, the non-emptiness of sets 2 and 3 implies that some projects would be initiated under conventional modes of financing, but not with ICO financing.

\section{Conclusion}

We set out to assess whether ICOs represent a worthwhile form of financing with beneficial economic properties when compared with conventional financing strategies. We find this to

\footnotetext{
${ }^{13}$ The minus signs denote the relative complement.
} 
Table II: Parameter Values for Examples Used in the Proofs

\begin{tabular}{|c|c|c|c|c|c|c|}
\hline Parameters & $\begin{array}{l}\text { Example } 1 \\
\text { (ICO best) }\end{array}$ & $\begin{array}{l}\text { Example } 2 \\
\text { (Debt best) }\end{array}$ & $\begin{array}{c}\text { Example } 3 \\
\text { (VC best) }\end{array}$ & $\begin{array}{l}\text { Example } 4 \\
\text { (only ICO) }\end{array}$ & $\begin{array}{l}\text { Example } 5 \\
\text { (only Debt) }\end{array}$ & $\begin{array}{l}\text { Example } 6 \\
\text { (only VC) }\end{array}$ \\
\hline$I_{0}$ & 1,500 & 1,500 & 1,500 & 2,000 & 2,000 & 1,500 \\
\hline $\bar{e}$ & 450 & 450 & 150 & 350 & 250 & 50 \\
\hline$r$ & 0.05 & 0.05 & 0.05 & 0.05 & 0.05 & 0.05 \\
\hline$p$ & 10 & 5 & 5 & 15 & 5 & 5 \\
\hline$p_{s}$ & 8 & 3 & 3 & 13 & 3 & 3 \\
\hline$\gamma$ & 0.5 & 0.5 & 0.5 & 0.5 & 0.5 & 0.5 \\
\hline$c_{H}$ & 1.5 & 1.5 & 1.5 & 1.5 & 1.5 & 1.5 \\
\hline$c_{L}$ & 1 & 1 & 1 & 1 & 1 & 1 \\
\hline$\delta$ & 0.5 & 0.5 & 0.5 & 0.5 & 0.5 & 0.2 \\
\hline$s_{L}$ & 100 & 150 & 100 & 150 & 150 & 100 \\
\hline$s_{H}$ & 250 & 200 & 250 & 200 & 200 & 250 \\
\hline
\end{tabular}

Note: The table provides the parameter values of the examples used in the proofs. The symbols have the following meanings: $I_{0}$ is the initial investment outlay, $\bar{e}$ is the non-pecuniary cost of effort, $r$ is the interest rate, $p$ is the reservation price of consumers, $p_{s}$ is the minimum dollar price at which merchants are willing to supply their product on the platform, $\gamma$ is the probability of success when effort is exerted, $c_{H}$ is the higher variable cost of operating the platform without successful effort, $c_{L}$ is the lower variable cost when successful effort occurs, $\delta$ is the probability that the state with higher consumer demand materializes, $s_{L}$ is lower level of consumer demand and $s_{H}$ is the higher level of consumer demand.

be true. All forms of financing we consider, including ICOs, can be inefficient. However, we demonstrate that, for certain projects, ICO financing generates a higher net present value than conventional modes of financing and is sometimes the only profitable form of financing.

The potential benefit of ICO financing arises from a better alignment of the incentives of the entrepreneur and the interests of investors. Crucial to this is the fact that the return to token investors under an ICO is based on the sales revenue of a project rather than profits. This can make things better in situations where effort by the entrepreneur leads to cost savings rather than higher sales. However, there is a potential downside. Our analysis reveals two issues associated with the use of ICOs as a means of financing that do not arise with conventional modes of financing. First, there is an upper limit on the fraction of future sales that can be shared with outside investors. Hence, it may be hard to finance a project 
Table III: Optimal Choices for the Entrepreneur Under Different Modes of Funding

\begin{tabular}{|c|c|c|c|c|}
\hline & Invest? & Effort if $s=s_{H}$ ? & Effort if $s=s_{L} ?$ & $\overline{N N P V^{J}}$ \\
\hline \multicolumn{5}{|l|}{ Example 1: } \\
\hline Deep Pockets & Yes & Yes & Yes & 571.43 \\
\hline Venture Capital & Yes & No & No & 166.67 \\
\hline Debt Financing & Yes & Yes & No & 547.62 \\
\hline Initial Coin Offering & Yes & Yes & Yes & 571.43 \\
\hline \multicolumn{5}{|l|}{ Example 2: } \\
\hline Deep Pockets & Yes & Yes & Yes & 571.43 \\
\hline Venture Capital & Yes & No & No & 166.67 \\
\hline Debt Financing & Yes & Yes & Yes & 571.43 \\
\hline Initial Coin Offering & No & - & - & 0 \\
\hline \multicolumn{5}{|l|}{ Example 3: } \\
\hline Deep Pockets & Yes & Yes & Yes & 857.14 \\
\hline Venture Capital & Yes & Yes & Yes & 857.14 \\
\hline Debt Financing & Yes & Yes & No & 690.48 \\
\hline Initial Coin Offering & No & - & - & 0 \\
\hline \multicolumn{5}{|l|}{ Example 4: } \\
\hline Deep Pockets & Yes & Yes & Yes & 166.67 \\
\hline Venture Capital & No & - & - & 0 \\
\hline Debt Financing & No & - & - & 0 \\
\hline Initial Coin Offering & Yes & Yes & Yes & 166.67 \\
\hline \multicolumn{5}{|l|}{ Example 5: } \\
\hline Deep Pockets & Yes & Yes & Yes & 261.90 \\
\hline Venture Capital & No & - & - & 0 \\
\hline Debt Financing & Yes & Yes & Yes & 261.90 \\
\hline Initial Coin Offering & No & - & - & 0 \\
\hline \multicolumn{5}{|l|}{ Example 6: } \\
\hline Deep Pockets & Yes & Yes & Yes & 309.52 \\
\hline Venture Capital & Yes & Yes & Yes & 309.52 \\
\hline Debt Financing & No & - & - & 0 \\
\hline Initial Coin Offering & No & - & - & 0 \\
\hline
\end{tabular}

Note: The table indicates the optimal choices for the entrepreneur when financing the projects in Table II under different modes of funding. The last column reports the net present value of the project that is achieved with each mode of funding. 
with an ICO when it requires a relatively large initial investment relative to potential future sales. Such a constraint is less likely to be binding for platform-like projects, where total sales revenue on the platform can be high, while the platform-owner takes only a small cut of the total sales by facilitating the activity on the platform. ${ }^{14}$ Second, there is the risk of token investors trying to increase their payoffs by trying to corner the market for tokens and increasing their payoffs. We show that this second issue does not occur in equilibrium as long as token ownership remains sufficiently widely dispersed.

When ICOs first broke onto the scene, there was a perception that this was a way for start-ups to raise money without giving away ownership in the company. There was a sense that ICOs allowed companies to obtain "money for nothing." Our results debunk this notion by showing that ICO funding generates no additional value beyond the increase in the value that results from a better alignment between the incentives of the entrepreneur and the interests of outside investors.

\footnotetext{
${ }^{14}$ The "sp" constraint could potentially be relaxed if the entrepreneur could commit to destroying coins in future periods or taking actions to reduce their velocity. Both options would change the cost of the commitments under the original arrangement. As such, it is an open question whether the full benefits of revenue sharing can be obtained within the confines of the ICO model.
} 
Figure 2: Optimal Strategy for the Entrepreneur for Different Levels of $s_{L}$ and $s_{H}$

(a) Deep Pockets

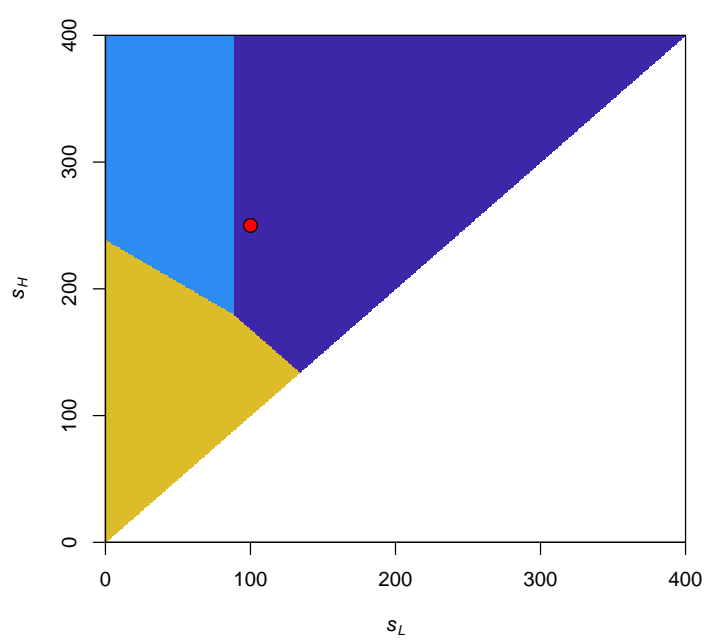

(c) Venture Capital

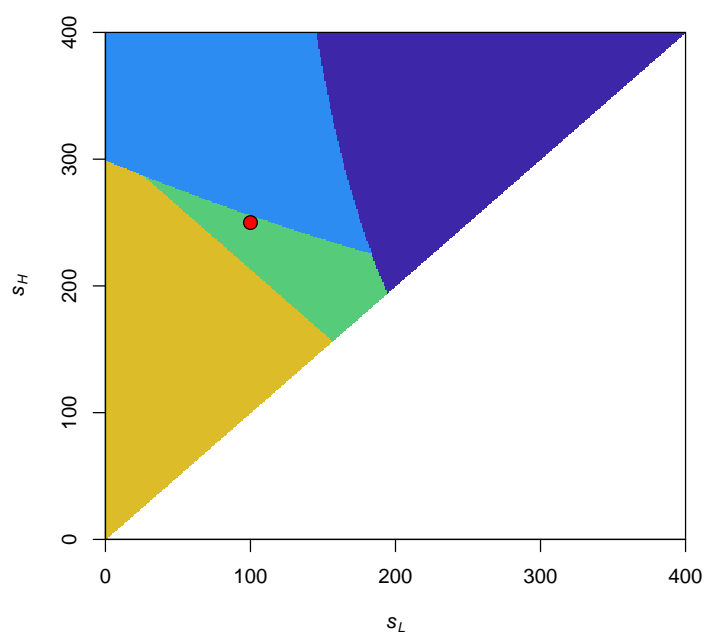

$\square$ No investment

Investment; effort only when $s=s_{H}$ (b) Debt Financing

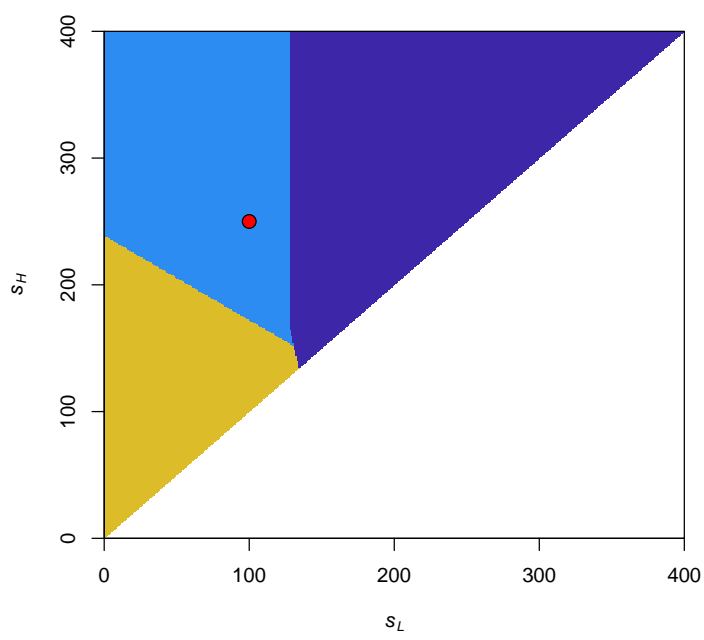

(d) Initial Coin Offering

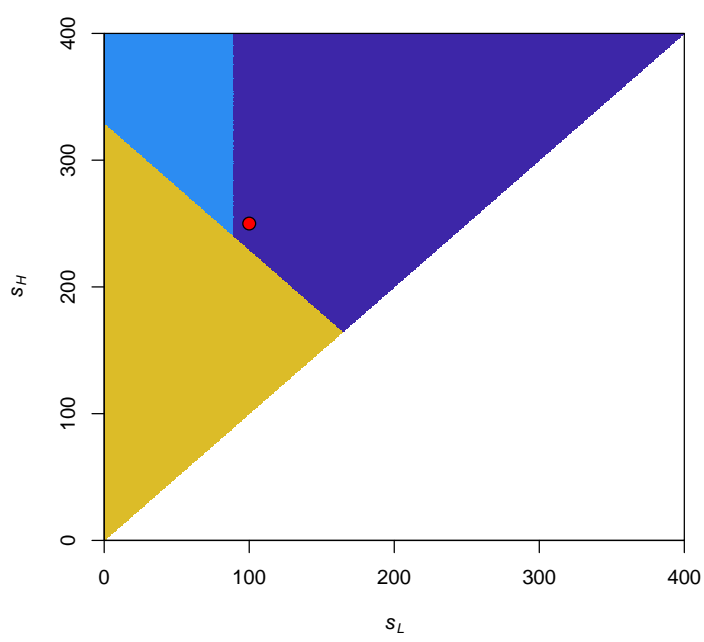

Investment; no effort

$\square$ Investment; always effort

Note: The colors indicate the optimal choices for the entrepreneur for projects that are characterized by different levels of potential demand $s_{L}$ (horizontal axis) and $s_{H}$ (vertical axis). The red circle coincides with example 1 in Table II. The parameter choices are the following: the investment outlay is $I_{0}=1,500$, the non-pecuniary cost of effort is $\bar{e}=450$, the interest rate is $r=0.05$, the reservation price of consumers is $p=10$, the minimum required dollar price by suppliers is $p_{s}=8$, the probability of success when effort is exerted is $\gamma=0.5$, the higher variable cost of operating the platform without successful effort is $c_{H}=1.5$, the lower variable cost when successful effort occurs is $c_{L}=1$ and the probability that the state with high demand $s_{H}$ materializes is $\delta=0.5$. 


\section{Appendix A: Token Ownership Distributions}

In this appendix, we provide examples of token ownership distributions under which investors liquidate all tokens at $t=2$ in equilibrium.

Case 1: Symmetric Nash equilibrium with $n$ large investors with equal amounts of coins $H^{i}=\phi M / n$ for all $i$.

For any symmetric Nash equilibrium, we have that $h_{2}^{-i}=(n-1) h_{2}^{N}$. From condition (21), we have that for any symmetric Nash equilibrium, when $h_{2}^{N}$ is not constrained by $H^{i}$, it must hold true that

$$
h_{2}^{N} \geq r(n-1) h_{2}^{N}+r(1-\phi) M \text {. }
$$

Using $H^{i}=\phi M / n$ for all $i$, this condition cannot hold true if (sufficient condition)

$$
n \geq \phi \frac{1+r}{r}
$$

Hence, if there is a sufficiently large number of investors with equal investments, then the constraint will kick in and they will optimally choose to liquidate their entire holdings in the first period.

\section{Case 2: Many very small investors and one large investor with $H^{i}$ coins.}

The constraint in (22) is binding for very small investors. So, the very small investors will liquidate all their coins in the first period, meaning that $h_{2}^{-i}=\phi M-H^{i}$. Substituting this expression into equation (21) produces a sufficient condition for the large investor to liquidate the entire holdings of $H^{i}$ coins in the first period:

$$
r\left(M-H^{i}\right) \geq H^{i}
$$


This means $h_{2}^{i}<H^{i}$ will not occur if the share of the tokens held by the large investor is sufficiently small:

$$
\frac{H^{i}}{M} \leq \frac{r}{1+r}
$$

Note the similarity of this sufficient condition with that for the situation where there are $n$ investors with equal shares and $\phi=1$.

\section{Appendix B: Calculations for Example 1}

Table BI: Valuation of Venture and Tokens at $t=2$ in Example 1

\begin{tabular}{lcccc}
\hline \hline Contingency & Units sold & Marginal cost & Present value at $t=2$ & Token value at $t=2$ \\
\hline$\left(c_{H}, s_{L}\right)$ & 100 & 1.50 & $1,000 * 1.05$ & 1,000 \\
$\left(c_{L}, s_{L}\right)$ & & 1.00 & $2,000 * 1.05$ & 1,000 \\
\hline$\left(c_{H}, s_{H}\right)$ & 250 & 1.50 & $2,500 * 1.05$ & 2,500 \\
$\left(c_{L}, s_{H}\right)$ & & 1.00 & $5,000 * 1.05$ & 2,500 \\
\hline \hline
\end{tabular}

Deep pockets: Stage 2 decision: Launch or not? The entrepreneur optimally sets $m^{*}=10-8=2$ and launches the platform because the present values calculated from equation (1) shown in Table BI are positive for all contingencies. Stage 1 decision: Exert effort or not? If $s=s_{H}$, then the entrepreneur exerts effort because it yields an expected payoff of $(5,000-2,500) / 2$ in terms of the $t=1$ present value, which exceeds the cost of effort of 450. If $s=s_{L}$, then the entrepreneur exerts effort because it yields an expected payoff of $(2,000-1,000) / 2$ in terms of the $t=1$ present value, which exceeds the cost of effort of 450. Stage 0 decision: Invest or not? The cost of effort and investment in terms of the $t=1$ present value equals $1,500 * 1.05+450=2,025$. The $t=1$ present value of the project, given that effort is always exerted and production always occurs, equals $10,500 / 4=2,625$. The $t=0$ net present value equals $(2,625-2,025) / 1.05=600 / 1.05$. So the entrepreneur invests and always exerts effort.

Debt: Stage 2 decision: Launch or not? The platform should always be launched because the present values calculated from equation (1) in Table BI are positive for all 
contingencies. Stage 1 decision: Exert effort or not? Here we have to account for the fact that the decision to exert effort and, hence, the likelihood that the debt contract will be repaid depend on the level of the debt; see equation (12). Given our specification of the debt contract in equation (13), we consider hypothetical scenarios for exerting effort starting with the case where effort is exerted in all cases. Suppose the entrepreneur always exerts effort. Then the hypothetical promised debt repayment at $t=2$ to finance 1,500 at $t=0$ equals $1.05 *[1,575-1,000 *(1 / 4)] /(3 / 4)=1.05 * 1,766 \frac{2}{3}$. It follows that if $s=s_{L}$, then the benefit of exerting effort to the entrepreneur in terms of $t=1$ present value equals $\left(2,000-1,766 \frac{2}{3}\right) / 2$, which is less than the cost of effort of 450, so effort would not occur; a contradiction. Suppose the entrepreneur exerts effort only when $s=s_{H}$. Then the hypothetical promised debt repayment at $t=2$ to finance 1,500 at $t=0$ equals $1.05 *[1,575-1,000 / 2] / 0.5=$ $1.05 * 2,150$. It follows that, if $s=s_{H}$, the benefit of exerting effort in terms of the $t=1$ present value equals $[(5,000-2,150)-(2,500-2,150)] / 2=1,250$, which exceeds the cost of effort of 450, so the entrepreneur will exert effort. Since the entrepreneur will exert effort when $s=s_{H}$, we have no contradiction. The promised debt repayment will be $1.05 * 2,150$ and effort occurs only when $s=s_{H}$. Stage 0 decision: Invest or not? The expected $t=1$ present value to the entrepreneur equals $[(5,000-2,150)+(2,500-2,150)] / 4=800$ and the expected cost of effort equals $450 / 2=225$. The $t=0$ net present value of the project equals $(800-225) / 1.05=575 / 1.05$. So the entrepreneur invests in the project, exerts effort only when $s=s_{H}$ and defaults on the debt when $s=s_{L}$.

Venture capital: Stage 2 decision: Launch or not? The platform should always be launched because the present values calculated from equation (1) in Table BI are positive for all contingencies. Stage 1 decision: Exert effort or not? Here we have to account for the fact that the decision to exert effort and, hence, the amount the shareholder receives depend on the equity share; see equation (15). Given our specification of the equity contract in equation (16), we consider hypothetical scenarios for exerting effort, starting with the case where effort is exerted in all cases. Suppose the entrepreneur always exerts effort. Then 
the hypothetical value of the project in terms of $t=1$ present value equals 2,625 , while the cost of the investment in terms of $t=1$ present value equals $1,500 * 1.05$. So the entrepreneur needs to offer a share to investors of $1,575 / 2,625=0.60$ when always exerting effort. If $s=s_{L}$, the benefit of effort to the entrepreneur in terms of $t=1$ present value equals $(1-0.60) *(2,000-1,000) / 2=200$, which is less than the cost of effort of 450 , so no effort would occur; a contradiction. Suppose the entrepreneur exerts effort only when $s=s_{H}$. Then the hypothetical value of the project in terms of $t=2$ present value equals $1.05 *(1,000+1,000+2,500+5,000) / 4=2,375$. So the entrepreneur needs to offer a share to investors of $w^{*}=1,575 / 2,375 \approx 0.6632$. The benefit of effort if $s=s_{H}$ in terms of $t=1$ present value equals $\left(1-w^{*}\right) *(5,000-2,500) \approx 421.053$, which is less than the cost of effort of 450, so effort would not occur; again, a contradiction. Suppose the entrepreneur never exerts effort. Then the hypothetical value in terms of $t=0$ present value equals $[(1,000+2,500) / 2] / 1.05=1,666.67$. So the entrepreneur needs to offer a share to investors of $w^{*}=1,500 / 1,666.67=0.9<1$. Since the entrepreneur never exerts effort and the equity share required by investors is less than 1 , there is no contradiction. Stage 0 decision: Invest or not? With venture capital, the project will occur, but the entrepreneur will never exert effort. The net present value of the project equals $1,666.67-1,500=166.67$.

ICO: Stage 2 decision: Launch or not? The present values calculated from equation (1) in Table BI are positive for all contingencies. Moreover, the entrepreneur will honor the commitment to accept the tokens because the $t=2$ present value of the project exceeds the $t=2$ token values. Since the platform is launched and the commitment is always honored, the value of the tokens will be independent of effort. The $t=2$ present value of the tokens is $0.5 *(2,500+1,000)=1,750$ and the cost of the project is $1,500 * 1.05^{2}$, so the share of tokens offered to investors needs to equal $\phi^{*}=1.05^{2} * 1,500 / 1,750=0.945$, which is smaller than one. Stage 1 decision: Exert effort or not? If $s=s_{L}$, the $t=1$ present value of the benefit of effort equals $[(2,000-1,000 / 1.05)-(1,000-1,000 / 1.05)]=500$, which is more than the cost of effort of 450, so effort occurs. Naturally, effort also occurs when $s=s_{H}$. 
As a consequence, the ICO replicates the efficient level of effort when the entrepreneur has deep pockets. Stage 0 decision: Invest or not? With the ICO, the project will occur and the entrepreneur always exerts effort. The net present value of the project when funded with the $\operatorname{ICO}$ is $(2,625-2,025) / 1.05=600 / 1.05$.

\section{References}

S. Athey, I. Parashkevov, V. Sarukkai, and J. Xia. Bitcoin Pricing, Adoption, and Usage: Theory and Evidence. Working Paper, 2016.

Y. Bakos and H. Hałaburda. The Role of Cryptographic Tokens and ICOs in Fostering Platform Adoption. Working Paper, 2018.

H. Benedetti and L. Kostovetsky. Digital Tulips? Returns to Investors in Initial Coin Offerings. Working Paper, 2018.

D. Bianchi and A. Dickerson. Trading Volume in Cryptocurrency Markets. Working Paper, 2018.

W. Bolt and M.R.C. Van Oordt. On the Value of Virtual Currencies. Journal of Money, Credit and Banking, forthcoming.

C. Catalini and J.S. Gans. Initial Coin Offerings and the Value of Crypto Tokens. NBER Working Paper, 24418, 2018.

J. Chod and E. Lyandres. A Theory of ICOs: Diversification, Agency, and Information Asymmetry. Working Paper, 2018.

L.W. Cong, Y. Li, and N. Wang. Tokenomics: Dynamic Adoption and Valuation. Working Paper, 2018.

A. De Jong, P. Roosenboom, and T. Van der Kolk. What Determines Success in Initial Coin Offerings? Working Paper, 2018. 
R.F. Dittmar and D. Wu. Returns to Initial Coin Offerings: An Empirical Examination. Working Paper, 2018.

Ernst \& Young. Initial Coin Offerings (ICOs): The Class of 2017 One Year Later. EY Study (October 19), 2018. URL https://www.ey.com/Publication/ vwLUAssets/ey-initial-coin-offerings-the-class-of-2017-one-year-later/\$FILE/ ey-initial-coin-offerings-the-class-of-2017-one-year-later.pdf.

R. Garratt and N. Wallace. Bitcoin 1, Bitcoin 2, ... : An Experiment on Privately Issued Outside Monies. Economic Inquiry, 56(3):1887-1897, 2018.

S. Govindan and R. Wilson. On Forward Induction. Econometrica, 77(1):1-28, 2009.

S.T. Howell, M. Niessner, and D. Yermack. Initial Coin Offerings: Financing Growth with Cryptocurrency Token Sales. NBER Working Paper, 24774, 2018.

A. Hu, C.A. Parlour, and U. Rajan. Cryptocurrencies: Stylized Facts on a New Investible Instrument. Working Paper, 2018.

M.C. Jensen and W.H. Meckling. Theory of the Firm: Managerial Behavior, Agency Costs and Ownership Structure. Journal of Financial Economics, 3(4):305-360, 1976.

J. Lee and C.A. Parlour. Crowdfunding, Initial Coin Offerings, and Consumer Surplus. Working Paper, 2018.

J. Lee, T. Li, and D. Shin. The Wisdom of Crowds and Information Cascades in Fintech: Evidence from Initial Coin Offerings. Working Paper, 2018.

J. Li and W. Mann. Initial Coin Offering and Platform Building. Working Paper, 2018.

K. Malinova and A. Park. Tokenomics: When Tokens Beat Equity. Working Paper, 2018.

S.C. Myers. Determinants of Corporate Borrowing. Journal of Financial Economics, 5(2): 147-175, 1977. 
Reuters. Vietnam Calls for Tougher Measures on Cryptocurrency Deals amid Alleged Scam. News Report (April 11), 2018. URL https://www.reuters.com/article/us-vietnam-cryptocurrency/ vietnam-calls-for-tougher-measures-on-cryptocurrency-deals-amid-alleged-scam-idUSKBN1HI1YV .

SEC. The SEC Has an Opportunity You Won't Want to Miss: Act Now! Press Release (May 16), 2018. URL https://www.sec.gov/news/press-release/2018-88.

R. Strausz. A Theory of Crowdfunding: A Mechanism Design Approach with Demand Uncertainty and Moral Hazard. American Economic Review, 107(6):1430-76, 2017. 